\title{
Nota ao editor
}

Prezado Editor, Dr. Eberval G. Figueiredo

Gostaria de fazer algumas considerações referentes ao artigo "Brazilian Neurointensive Care: a brief history" publicado nesta conceituada revista (Arq Bras Neurocir. 2011;30(4):166-8). A primeira Unidade de Terapia Intensiva Neurológica da Beneficência Portuguesa foi fundada em 1990 pelo Prof. Dr. Raul Marino Junior com posterior inauguração, em 1997, da UTI do Prof. Dr. Walter Carlos Pereira. A partir de 2005, houve unificação das Unidades e estas estão sob minha coordenação desde então, não estando vinculadas à equipe médica do Hospital Santa Catarina, conforme consta no artigo. Atualmente, com 33 leitos, somos a maior UTI Neurológica do país.

Atenciosamente,

Salomón Soriano Ordinola Rojas Coordenador das UTIs Neurológicas

Hospital Beneficência Portuguesa 